\title{
Bandwidth Enhancement of rectangular dielectric resonator antenna using circular and sector slot coupled technique
}

\author{
C. Zebiri ${ }^{1}$, M. Lashab ${ }^{2}$, D. Sayad ${ }^{3}$, I.T.E. Elfergani ${ }^{4}$, J. Rodregiez ${ }^{4}$, F. Benabdelaziz ${ }^{3}$, R. A. Abd-Alhameed ${ }^{5}$ \\ ${ }^{1}$ University of Ferhat Abbas, Setif -1-, 19000 Setif, Algeria (e-mail: czebiri@ univ-setif.dz, zebiri@ymail.com) \\ ${ }^{2}$ Department of Electronics, University of Oum-elbouagui, 4000 Oum-elbouagui, Algeria \\ ${ }^{3}$ Department of Electrical Engineering, 20 Aout 1955 University, 21000 Skikda, Algeria. \\ ${ }^{4}$ Instituto de Telecomunicações, Portugal
}

${ }^{5}$ School of Electrical Engineering and Computer Science, University of Bradford, BD71DP, UK (e-mail: r.a.a.abd@bradford.ac.uk).

\begin{abstract}
In this paper, investigations are being given to improve the antenna performance. A dielectric resonator antenna (DRA) is designed and simulated using the commercial software HFSS, the circular with other sections slot coupled technique is used to enhance the bandwidth in particular and the antenna improve the antenna performance in general. And the antenna $1.08 \mathrm{GHz}$ and $1.75 \mathrm{GHz}$
\end{abstract}

Index Terms-antenna, propagation, measurement.

\section{INTRODUCTION}

The defected ground plane has taken much attention in the fields of microwave and millimetre wave applications. In this technology, defects of certain lattice forms are etched in the ground plane that will disturb the current distribution in the microwave structure [1] [2]. Recently, the operated bandwidth of antennas using DRAs have been further improved for ultrawideband applications [3][4][5][6]. Aperture coupling, probably one of the most common feeding structures, consists in coupling energy into the resonator through an aperture in its ground plane. Two cylindrical dielectric resonators, which are asymmetrically located with respect to the center of rectangular coupling aperture, are feds through the aperture of the ground plan with a slotted microstrip line antenna. By optimizing the design parameters, an impedance bandwidth of about $46 \%$, covering the frequency range from $9.1 \mathrm{GHz}$ to 14.6 GHz, and a simulated gain of $8 \mathrm{dBi}$ are obtains [4]. In [7], a DGS annular ring was examined. The application was extended to dielectric resonator antennas (DRAs), the stopband property of this configuration is used to suppress mutual coupling between two circular microstrip patches. Moreover, various geometries of DRAs such as conical [8], cylindrical [9] where it was used in the first candidate, investigated as radiating element [10], tetrahedral [11], elliptical [12], and the use of hybrid hemispherical-conical-shaped [13], were all of the proposed structure are for a bandwidth enhancement techniques. In recent published work [6] that provided the inspiration for the current research work a compact ultrawideband DRA is presented. The work studied two cylindrical DRs configuration, asymmetrically placed around the center of an offset rectangular coupling aperture in which a $62 \%$ bandwidth, covering two frequency bands: 5.9-
$7.32 \mathrm{GHz}$ and $8.72-16.57 \mathrm{GHz}$, and a gain of $8 \mathrm{dBi}$ were achieved.
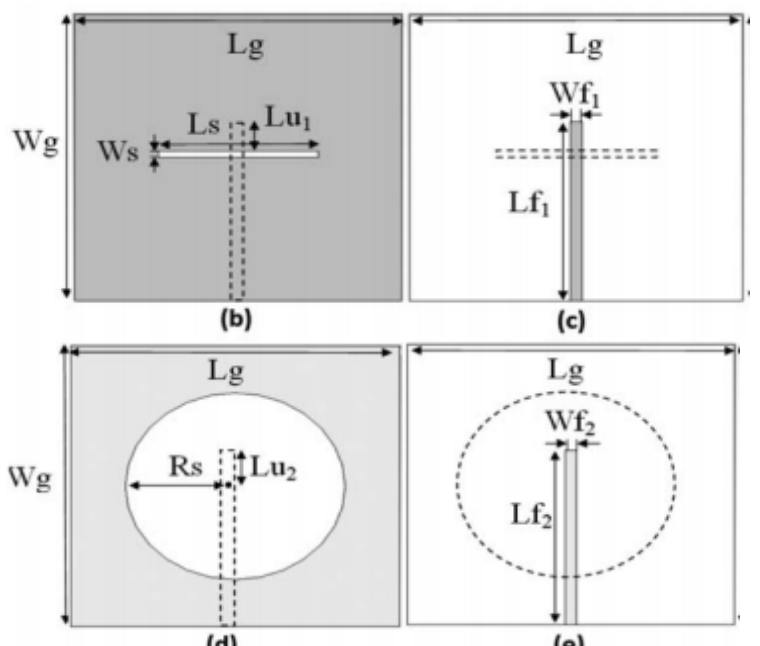

(d)

(e)

Figure 1: Setup of the proposed antenna: (b) and (c) top view bottom view of the antenna with rectangular slot (antenna1); (d) and (e) top view and bottom view with circular slot (antenna2).

Table 1: Dimensions of the parameters.

\begin{tabular}{|c|c|c|c|c|c|}
\hline parameter & $\begin{array}{c}\text { Dimension } \\
(\mathrm{mm})\end{array}$ & parameter & $\begin{array}{c}\text { Dimension } \\
(\mathrm{mm})\end{array}$ & parameter & $\begin{array}{c}\text { Dimension } \\
(\mathrm{mm})\end{array}$ \\
\hline $\mathbf{W}_{\mathbf{g}}$ & 90 & $\mathbf{W}_{\mathbf{f 1}}$ & 3.18 & $\mathbf{W f 2}$ & 3.38 \\
\hline $\mathbf{L}_{\mathbf{g}}$ & 90 & $\mathbf{L f 1}$ & 56.56 & $\mathbf{W d}$ & 70 \\
\hline $\mathbf{W}_{\mathbf{s}}$ & 2 & $\mathbf{R}_{\mathbf{s}}$ & 35 & $\mathbf{L d}$ & 70 \\
\hline $\mathbf{L s}$ & 44 & $\mathbf{L u 2}$ & 11 & $\mathbf{H d}$ & 14 \\
\hline $\mathbf{L u} \mathbf{1}$ & 9.56 & $\mathbf{L f 2}$ & 56 & $\mathbf{S h}$ & 1.52 \\
\hline $\mathbf{S}_{\mathbf{w}}$ & 90 & $\mathbf{S}_{\mathbf{l}}$ & 90 & & \\
\hline
\end{tabular}

Our study is based on the published paper in the literature; this is dealing with the enhancement of the bandwidth of a rectangular DRA using circular slot [5]. In this paper it is noticed that a circular slot enhance the bandwidth up to $36,44 \%(0,92-1,33 \mathrm{GHz})$ almost 6 times than the rectangular slot $(6,39 \%(1,06-1,13 \mathrm{GHz}))$.

\section{PROPOSED ANTENNA AND SUMMARIZED RESULTS}

\section{A. Geometry of the proposed antenna}

The two studied structures are presented in Figure 1 for which their geometrical dimensions are given in Table 1 . The 
antenna geometry was a modified version of the work presented in [5].

The dimension of the DRA antenna with rectangular shape are $\mathrm{W}_{\mathrm{d}} \times \mathrm{L}_{\mathrm{d}} \times \mathrm{H}_{\mathrm{d}}$, they are calculated using dielectric waveguide model (DWM), owing to the fact of radiation in the free space, also by tuning the operating frequency to $1 \mathrm{GHz}\left(\mathrm{f}_{0}=1 \mathrm{GHz}\right)$ and maintaining the thickness to $\mathrm{W}_{\mathrm{d}}=14 \mathrm{~mm}$, the length and wideness are given as $\mathrm{L}_{\mathrm{d}} \times \mathrm{H}_{\mathrm{d}}=70 \mathrm{~mm} \times 70 \mathrm{~mm}$. A dielectric with permittivity $\left(\varepsilon_{\mathrm{r}}\right)$ of 7.85 is used to design the DRA. The transmission line and ground plane are implemented on a substrate Taconic RF 35 with permittivity of 3.5.

The DR is place in the middle of the antenna in order that all the surface of the slot will be covered and the analysis of the antenna will be easily done (Figure 2).

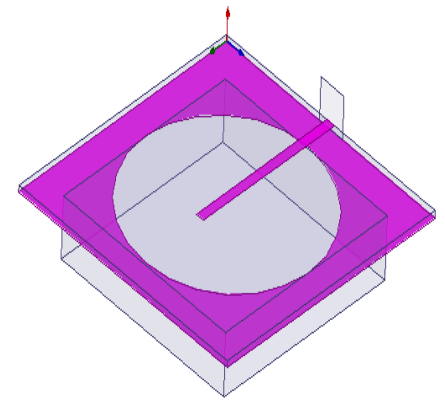

Figure 2. Design of the proposed DRA antenna using HFSS.

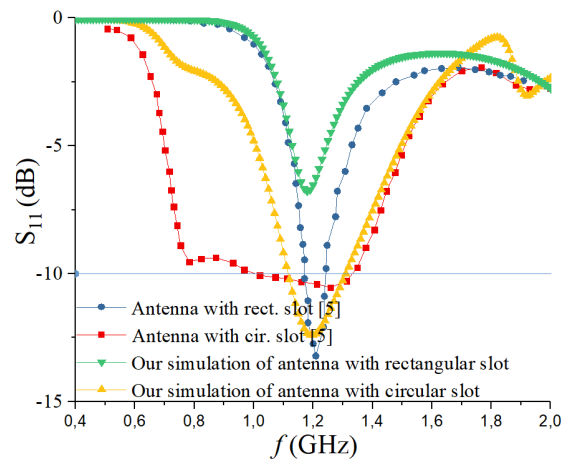

Figure 3: Validation of obtained results with those of reference [5].

The circular slot is used as coupler [13], also as radiator [14]. This was mainly for ultra-wide band (UWB) applications, with the possibility to obtain a bandwidth of $3.1 \mathrm{GHz}$ to $10.6 \mathrm{GHz}$. In order to attain this wide bandwidth, the circular slot has been used to replace the rectangular slot in the set up of the RD antenna, as given in [5]. Experimentally, the insertion of the circular slot has improved the bandwidth more than five times [5], (more than 30\%) compared to the rectangular slot, unfortunately this case has not been confirmed by our simulation Figure 3 .

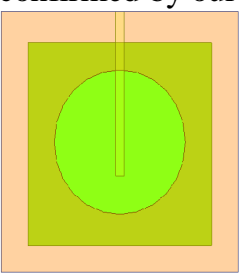

Step 1

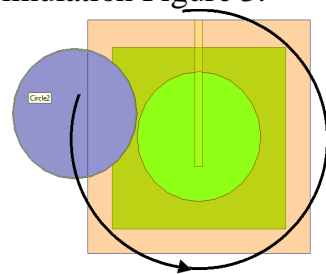

Step 2

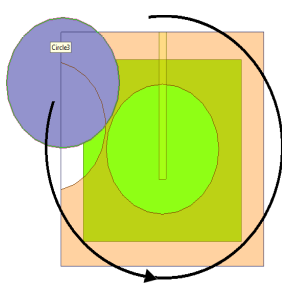

Step 3
Figure 4.a: Different steps of the design on HFSS.

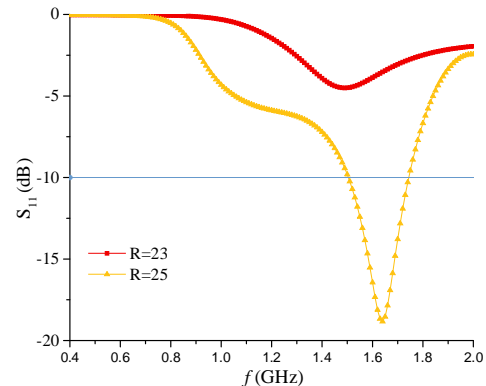

Figure 4.b: (Step 1) Return loss Coefficient $\left(\mathrm{S}_{11}\right)$ of different steps of the design on HFSS
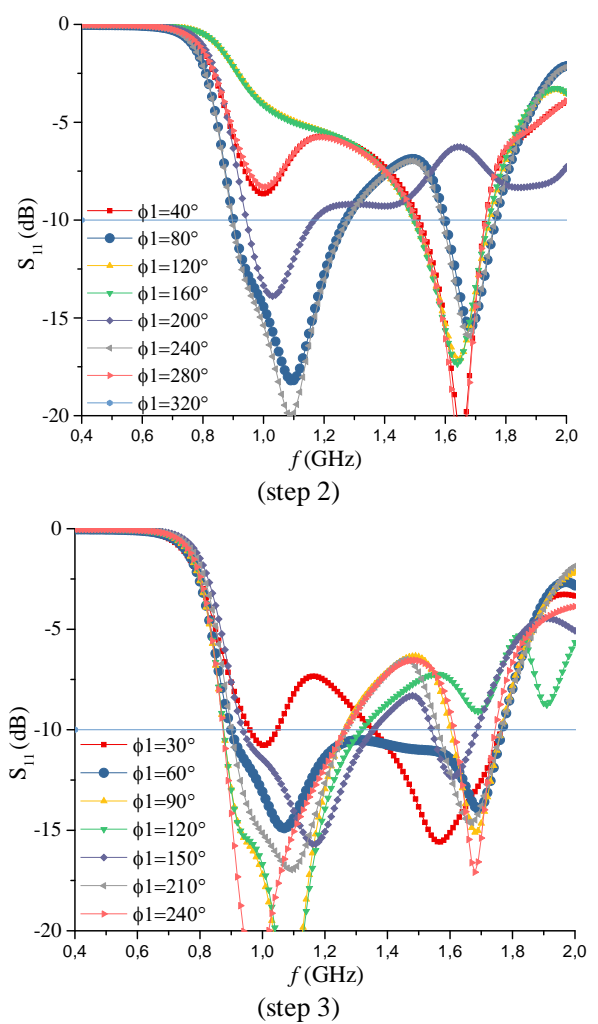
HFSS

Figure 4.b: Return loss Coefficient $\left(S_{11}\right)$ of different steps of the design on

\section{B. Analysis of Results}

Figure 3 shows the comparison of the return loss S11 between those obtained by CST and published in [5] and the results obtained by HFSS in this paper. According to this figure it can be noticed that the behavior of S11 of the antenna1 is very close to our results. Contrary to the case of antenna 2, (with circular slot), where the results are different, this can be explained by the difference of simulation software, but fortunately the proposed structure has been improved by adding two more circular slots, better results has been obtained regarding the two antennas (1 and 2).

\section{Results validation}

In order to improve our structure, three steps are presented, the first is the reduction of the radius of the central circle to $\mathrm{R}=25 \mathrm{~mm}$ which allow to insert a slot of circular form, the optimal position of this circle is $\varphi_{1}=80^{\circ}$, another slot is inserted, its parfait position for better return loss $S_{11}$, is $\varphi_{2}=60^{\circ}$, this is well illustrated by Figure 4 ( $a$ and $b$ ). 


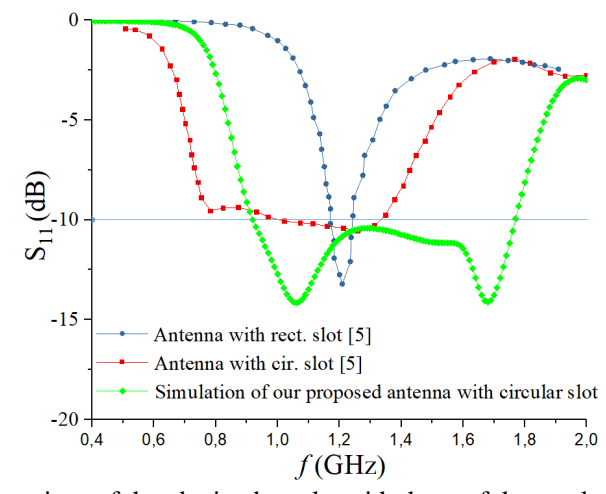

Figure 5: comparison of the obtained results with those of the results from [5].

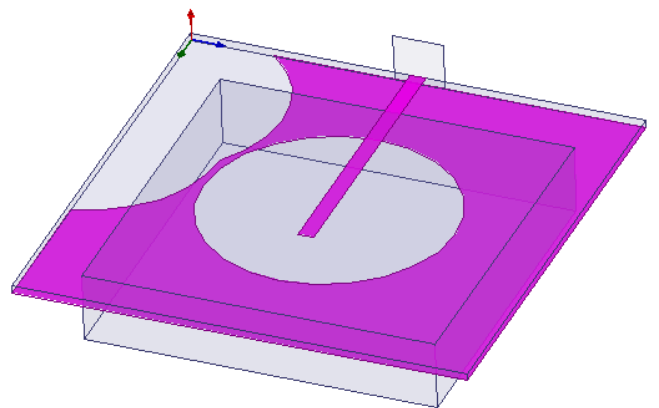

Figure 6. The proposed structure with rectangular DRA.

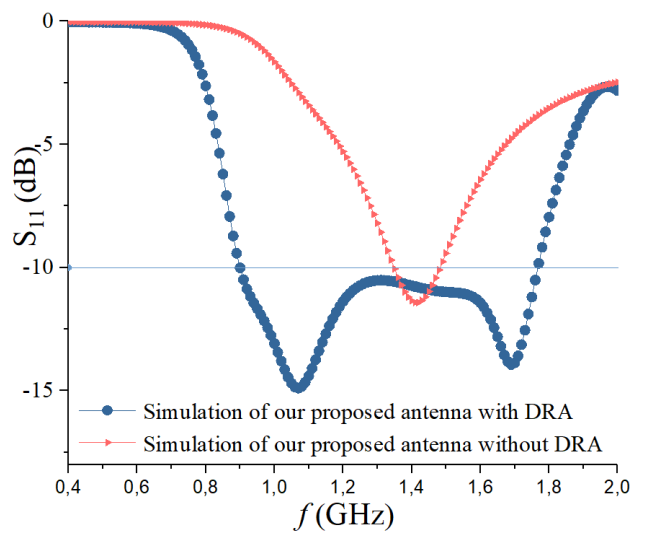

Figure 7: Return loss coefficient (S11) of the proposed structure with and without DRA Rectangular aperture

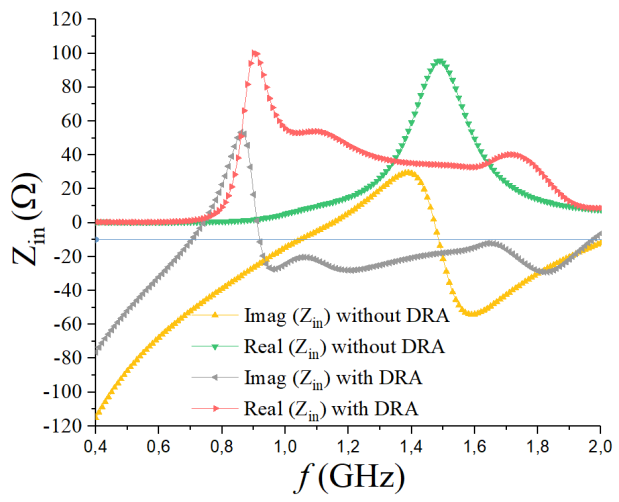

Figure 8: Input impedance of the proposed DRA structure with and without rectangular aperture

Figure 5 presents comparison between the return loss coefficient S11 obtained in our simulation and the return loss given in [5] for the two antennas. It is very clear that the proposed antenna (Figure 6) operates at $0.87-1.8 \mathrm{GHz}(68.9 \%)$, but the antenna in [5] with circular slot operates at 0.8-1.4
$\mathrm{GHz}(54.6 \%)$. One can notice that there is an increase of $25 \%$ in the bandwidth of the proposed and simulated antenna.

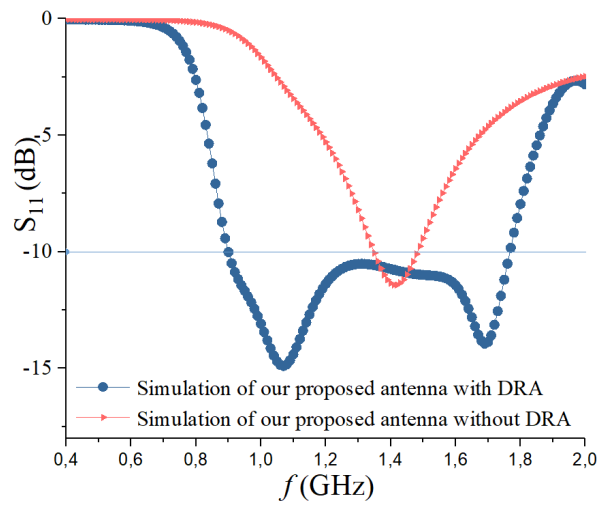

Figure 7: Return loss coefficient (S11) of the proposed structure with and

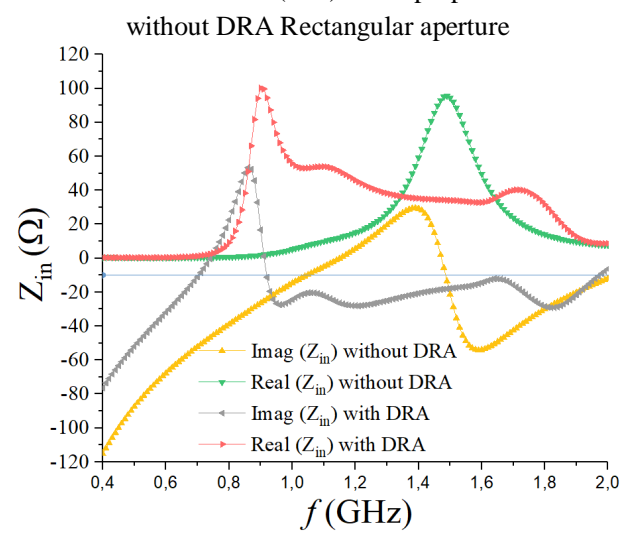

Figure 8: Input impedance of the proposed DRA structure with and without rectangular aperture

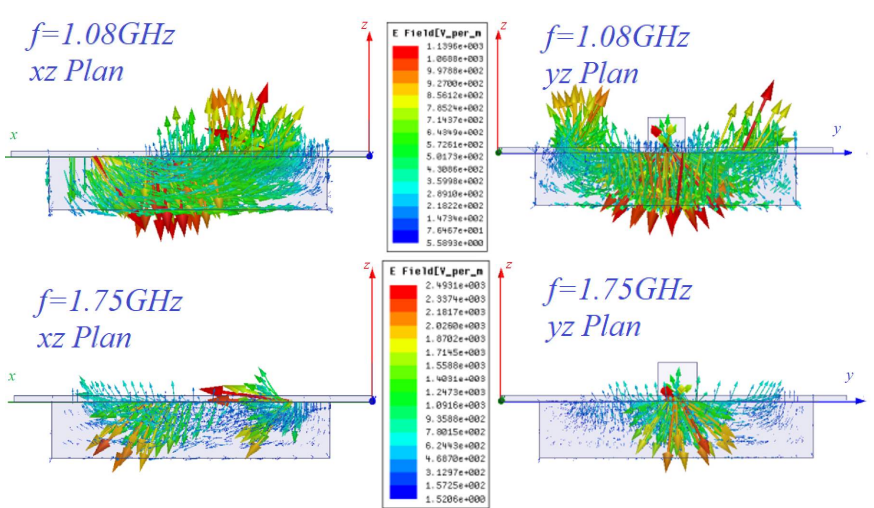

Figure 9: Electric field distribution in meridian plan zx and zy at the frequencies 1.08 and $1.75 \mathrm{GHz}$

Figures 7 and 8 present respectively the return loss coefficient $S_{11}$ and the input impedance of the proposed antenna with and without RDRA. It is noticed that the defected ground plane present resonance at $1.5 \mathrm{GHz}$, and the created modes in the RDRA are respectively at the frequencies 0.9 , 1.08 and $1.7 \mathrm{GHz}$. The frequencies close to the three resonant lead to antenna with large band.

The separation between the two modes depends on the relative dimension of the resonator. In this case, in order to define exactly the coupled mode of the resonator, it is 
necessary to know the electric field repartition of the two modes. Figure 9 shows this repartition in the yz plan. We notice that the degenerated modes shown by Figure 9 are the modes $\mathrm{TE}_{11 \delta}$ and $\mathrm{TE}_{12 \delta}$, we notice that the two modes present similar partition for the electric field.

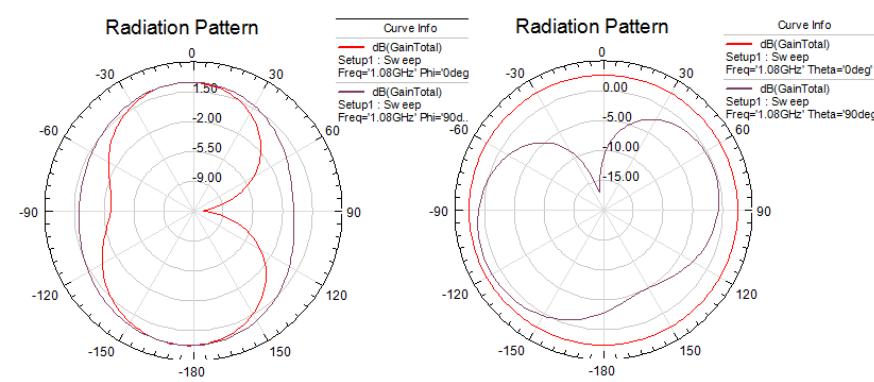

Figure 10: Simulated radiation pattern of the proposed DRA at $1.08 \mathrm{GHz}$

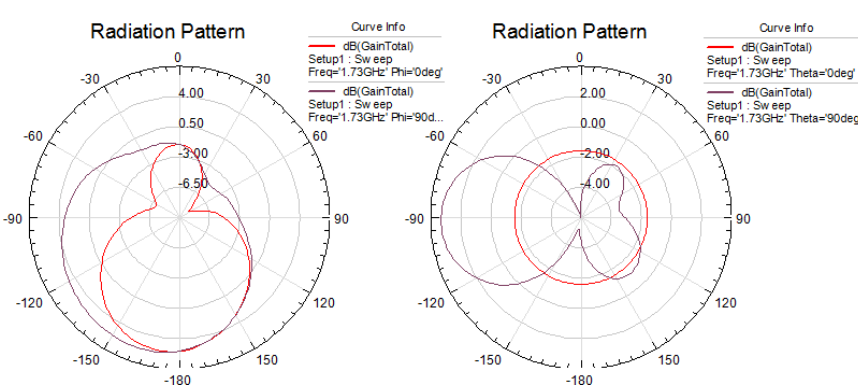

Figure 11: Simulated radiation pattern of the proposed DRA at $1.73 \mathrm{GHz}$

Figure 10 and Figure 11 present the simulated radiation pattern of the proposed DRA in the main plans, E-plan and $\mathrm{H}$ plan respectively at $1.08 \mathrm{GHz}$ and $1.75 \mathrm{GHz}$. It seems that the proposed antenna has bidirectional diagram in the E-plan and almost omnidirectional diagram in the H-plan in all the frequency range.

\section{CONCLUSION}

The dielectric resonator antennas (DRA) of rectangular shape, with circular slot, are polarized by microstrip line, for UWB application, are being simulated.

The design and simulation of the proposed structure is curried out using the commercial software HFSS, the obtained results show that the circular slot dimension affects directly the enhancement of the bandwidth and the miniaturization effect.

The two simulated antennas are operating in the frequency range of $0.87 \mathrm{GHz}-1.8 \mathrm{GHz}$. In addition they cover many applications such as: the talkie-walkie, the digital television and radio frequency (RFID-UHF). They can be also used for mobile communication, marine, aviation, and terrestrial vehicle.

\section{REFERENCES}

[1]L. H. Weng, Y. C. Guo, X. W. Shi, and X. Q. Chen "An Overview On Defected Ground Structure," Progress In Electromagnetics Research B, Vol. 7, 173-189, 2008.

[2] C Zebiri, D. Sayad, NT Ali, M. Lashab, F. Benabdelaziz , R.A. AbdAlhameed I.T.E.Elfergani and J. Rodriguez, "Reduced Ground Plane Aperture-Coupled DRA Fed by Slotted Microstrip for Ultra-Wideband Application", 2017 11th European Conference on Antennas and Propagation (EUCAP), pp 965-969, 2017.
[3] C Zebiri, F. Benabelaziz, M. lashab, D. Sayad, F. Elmegri, I.T.E.Elfergani, N.T. Ali, Abubakar Sadiq Hussaini, R. A. AbdAlhameed and Jonathan Rodriguez, "Aperture-Coupled Asymmetric Dielectric Resonator Antenna with Slotted Microstrip line for Enhanced UltraWideband", Antennas and Propagation (EuCAP), 2016 10th European Conference on. IEEE, 2016.

[4] M. Khalily, M. Ramlee K. S. Danesh, "Planar wideband circularly polarized dielectric resonator antenna", Antennas and Propagation Society International Symposium (APSURSI) 2013 IEEE, pp. 12381239, 2013.

[5] Sukur, M. I. A., Rahim, M. K. A., \& Murad, N. A. (2016). Bandwidth enhancement of rectangular dielectric resonator antenna using circular slot coupled technique. Microwave and Optical Technology Letters, 58(3), 505-509.

[6] C-E Zebiri, M. Lashab, D. Sayad, I.T.E. Elfergani, K.H. Sayidmarie, F. Benabdelaziz, R.A. Abd-Alhameed, J. Rodriguez, J.M. Noras "Offset Aperture-Coupled Double-Cylinder Dielectric Resonator Antenna with Extended-Wideband", IEEE Transactions on Antennas and Propagation, 2017, vol. 65, no 10 , p. 5617-5622.

[7] D. Guha, S. Biswas, T. Joseph and M. T. Sebastian, "Defected ground structure to reduce mutual coupling between cylindrical dielectric resonator antennas", Electronic Lett. ,vol. 44, no.14,pp. 836 - 837. July 2008.

[8] A. A. Kishk, Y. Yin, and A, W. Glisson, "Conical dielectric resonator antennas for wideband applications," IEEE Trans. Antennas Propag., vol. 50, pp. 469-474, Apr. 2002.

[9] Majeed, A. H., Abdallah, A. S., Elmegri, F., Sayidmarie, K. H., AbdAlhameed, R. A., \& Noras, J. M. (2014). Aperture-Coupled Asymmetric Dielectric Resonator Antenna for Wideband Applications.

[10] S. A. Long, M. W. McAllister, and L. C. Shen, "The resonant cylindrical dielectric cavity antenna," IEEE Trans. Antennas Propag., vol. AP-31, no. 3, pp. 406-412, May 1983.

[11] A. A. Kishk, "Wideband dielectric resonator antenna in a truncated tetrahedron form excited by a coaxial probe," IEEE Trans. Antennas Propag., vol. 51, no. 10, pp. 2907-2912, Oct. 2003.

[12] S. S. Yang, R. Chair, A. A. Kishk , K. F. Lee and K. M. Luk "Study on sequential feeding networks forsubarrays of circularly polarized elliptical dielectric resonator antenna", IEEE Trans. Antennas Propag., vol. 55, no. 2 , pp.321 -3332007

[13] Guha, Debatosh, Bidisha Gupta, and Yahia MM Antar. "Hybrid monopole-DRAs using hemispherical/conical-shaped dielectric ring resonators: Improved ultrawideband designs." Antennas and Propagation, IEEE Transactions on 60.1 (2012): 393-398. 